\title{
An observational study of pediatric healthcare burden in Angelman syndrome: results from a real-world study
}

\author{
Nasreen Khan ${ }^{1^{*}}$ (D), Raquel Cabo ${ }^{1}$, Wen-Hann Tan², Regina Tayag ${ }^{3}$ and Lynne M. Bird ${ }^{4}$
}

\begin{abstract}
Background: The objective of this study is to describe variations in the healthcare resource utilization (HRU) among individuals with Angelman syndrome (AS) over the first 12 years of life. Data for this study were drawn from the AS Natural History study (ASNHS), which is an observational study on the developmental progress, behavior, and medical morbidity of individuals with AS conducted over eight years. Caregiver-reported information on hospitalization, surgery, and medication utilization was used to assess HRU. Repeated measures mixed effect models were used to assess the relationship between age and probability of hospitalization, surgery, and prescription medication utilization.

Results: Mean age at study enrollment was 6 years of age and both sexes were equally represented. The mean number of visits per participant was three. Results from this study suggest that individuals with AS have a high HRU burden. Hospitalization and surgery burden were highest in the first year of life. Use of medications for seizures and sleep disturbance increased over time.

Conclusions: The study highlights the significant healthcare burden among individuals with AS. Future studies that estimate cost and caregiver burden associated with AS are needed to assess the lifelong economic impact of AS on families and healthcare system.
\end{abstract}

Keywords: Healthcare economics, Healthcare resource utilization, Rare disease, Disease burden

\section{Background}

Angelman syndrome (AS) is a rare, neurodevelopmental condition characterized by severe impairment in behavior, motor function, sleep, and cognition. There are no approved treatments for AS and the current goal is management of comorbidities and symptoms [1]. AS has an impact on overall health, severely limiting activities of daily living and individuals require lifelong support from a network of specialists and caregivers.

There is limited information on the healthcare burden of individuals with AS and how it varies with age. In a study of 34 individuals with a mean age of 21.6 years, [2] Thomson et al. found that individuals with AS had a high hospitalization burden (median of 5.5 hospitalizations per person) and the most common reasons for hospitalization

\footnotetext{
* Correspondence: Nasreen.khan@rwecon.com

'RWEC LLC, 73 Walsingham, Mendham, NJ 07945, USA

Full list of author information is available at the end of the article
}

were seizures, gastrointestinal disorders, and dental work. Another study found that the most common reasons for hospitalization were dental care, seizures, orthopedic problems, and acute respiratory disorders [3]. Our previous analysis using data from baseline visits of the AS Natural History Study (ASNHS) found that more than $60 \%$ of individuals had a history of at least one hospitalization from birth to enrollment into the study [4]. The most common reasons for hospitalizations were seizures, lower respiratory infections, and surgery. The most commonly used medications were those for treatment of seizures, gastroesophageal reflux disease, sleep, and behavioral disorders. In addition, our study showed that individuals with AS had high utilization of supportive therapies, such as early childhood intervention and physical, occupational, and speech therapies to promote development.

While the above studies have established the significant healthcare burden for individuals with AS, there are no published data on how this burden changes with age. The

(c) The Author(s). 2019 Open Access This article is distributed under the terms of the Creative Commons Attribution 4.0 International License (http://creativecommons.org/licenses/by/4.0/), which permits unrestricted use, distribution, and 
primary aim of this study is to describe how healthcare resource utilization (HRU) varies with age in the pediatric population with AS in the United States (US). By documenting the HRU among children with AS, we will begin to characterize the unmet needs for this population, which may help determine how resources should be allocated for the management of this chronic condition.

\section{Methods}

\section{Data}

The ASNHS gathered longitudinal data on the developmental progress, behavior, and medical morbidity of individuals with AS from 2006 to 2014 [5]. The study was conducted by the Angelman, Rett, and Prader-Willi Syndromes Consortium of the NIH Rare Diseases Clinical Research Network (ClinicalTrials.gov Identifier: NCT00296764). Individuals with AS were recruited at six study sites across the United States. Inclusion criteria included a molecular or clinical diagnosis of AS, and age between 1 day and 60 years. A total of 311 individuals were enrolled in the ASNHS. For the purpose of this analysis, only 302 individuals with molecularly confirmed AS and no concomitant medical condition (similar intellectual disability) were included.

At the baseline visit and at each annual follow-up visit, data were collected through interviews with the caregiver who was present at the visit about the participant's previous and current medical history and developmental progress since birth. With respect to HRU, the dates of, and indications for, any hospitalization or surgery, and length of stay (LOS) were recorded. Information was also collected on the use of prescription and non-prescription medications, including the reasons for using each medication and the duration of use.

The date of event (e.g., hospitalization) and date of birth were used to calculate the age at time of event, if age was not directly reported. If the event date was completely missing, the date of visit at which the event was reported was used to calculate the age at time of event, provided that no more than one annually scheduled visit was missing immediately prior to the visit reporting the event. If there was more than one missing annual visit immediately prior to the visit reporting the event, then age at time of event was considered missing and not included in the analysis. As we could not determine whether a given surgery was performed in an outpatient or inpatient setting, hospitalization and surgery data were not considered mutually exclusive. In addition, length of stay (LOS) was defined as the number of nights in a hospital, with a minimum of one overnight stay in the hospital. Finally, analyses were restricted to individuals 12 years of age or younger due to small sample sizes for older age groups.

\section{Statistical analysis}

Descriptive statistics of the resource utilization in the sample are presented by age. For continuous variables, the mean and standard deviation (SD) are presented. For categorical variables, frequencies and related percentages are presented. To analyze how healthcare utilization changes with age, a mixed model for repeated binary measurements was used. Separate models were fitted to estimate the probability of hospitalization, surgery, and prescription medication utilization. Models included fixed effects for intercept, age, molecular genotype, and genotype-by-age interaction, and random effects for intercept and slope. Molecular genotype was defined as a binary measure where individuals with a deletion genotype were categorized together and individuals with non-deletion etiology were categorized otherwise, as the reference category. Molecular etiology was added as a covariate since previous studies suggested that individuals with deletion genotype generally have a more severe course [5-9]. All statistical analyses were performed using SAS ${ }^{\bullet}$ Version 9.4 or higher for Windows.

\section{Results}

Table 1 shows basic demographic information and available data at the time of enrollment. Mean age at AS diagnosis was two years and $48 \%$ were male. Most of the participants (62\%) were less than five years old at the time of enrollment. On average, individuals had approximately three annual visits, including the baseline visit during which historical data were collected. Figure 1 shows the number of

Table 1 Baseline descriptive data and data availability in this study

\begin{tabular}{ll}
\hline Variable & $N=302$ \\
\hline Age at diagnosis, years (mean, SD) & $2(3)$ \\
Male (n, \%) & $145(48 \%)$ \\
Age at baseline, years (mean) & $5.5(5.9)$ \\
$0-1$ year $(n, \%)$ & $53(18 \%)$ \\
2 years $(n, \%)$ & $61(20 \%)$ \\
3 years $(n, \%)$ & $37(12 \%)$ \\
4 years $(n, \%)$ & $35(12 \%)$ \\
5 years $(n, \%)$ & $20(7 \%)$ \\
6 years $(n, \%)$ & $11(4 \%)$ \\
7 years $(n, \%)$ & $8(3 \%)$ \\
8 years $(n, \%)$ & $11(4 \%)$ \\
9 years $(n, \%)$ & $14(5 \%)$ \\
10 years $(n, \%)$ & $9(3 \%)$ \\
11 years $(n, \%)$ & $7(2 \%)$ \\
12 years $(n, \%)$ & $9(3 \%)$ \\
$>13$ years $(n, \%)$ & $25(8 \%)$ \\
Number of visits, (mean, min-max) & $3.3(1-9)$ \\
\hline
\end{tabular}




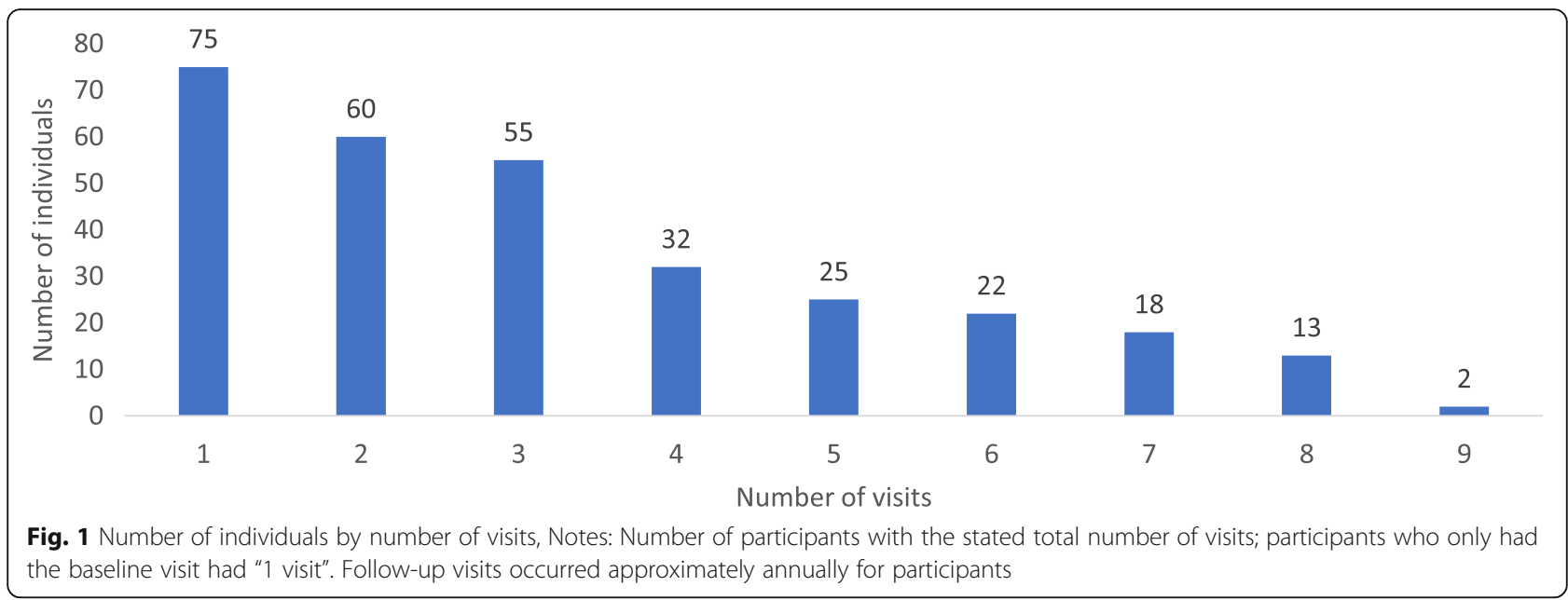

participants with the stated total number of visits. Approximately, $75 \%$ of individuals had at least two visits, $55 \%$ had at least three or more visits, and $37 \%$ had four or more visits.

Table 2 presents descriptive statistics on HRU by age. The occurrence of hospitalization was highest at $43 \%$ at age one year or younger, decreased over time, and was only $11 \%$ at age 12 years. There was a slight decrease (27\%) in the mean number of hospitalizations over time from 1.5 hospitalizations by age one to 1.1 hospitalizations at age 12 years. Among those hospitalized, mean LOS was 6.5 days at age one year (SD: 8.9), 3.6 days (SD: 5.8 ) at six years and 1.5 days (SD: 0.71 ) at 12 years. Seizures and lower respiratory infection were the most common reason for hospitalization. Similarly, surgeries were more common in the younger patients: $29 \%, 9 \%$, and $5 \%$ at age one year, six years, and 12 years, respectively. Tympanostomy tube insertion, strabismus correction, and tonsillectomy and adenoidectomy were the most frequent surgeries in this sample and were more common in infancy. Majority of individuals used one or more prescription medications and utilization increased with age ( $51 \%$ by age one year to $83 \%$ at age 9 years), after which a slight decline was observed. The mean number of prescription medication utilization increased by $26 \%$ between age one year and age 12 years, with the increase being non-linear. Use of anticonvulsant medications increased from $32 \%$ at age one year to $73 \%$ at age seven years and stabilized thereafter. Use of medications to treat GERD decreased from $27 \%$ at age one year to $13 \%$ at age six years and stabilized thereafter. Notably, there was an increase in the number of individuals using medications for behavioral and mental health indications, which increased from $1 \%$ in the younger years to $23 \%$ at age 12 years. Similarly, there was an increase in the number of individuals using non-prescription sleep medications: $18 \%$ by the first year of life, $37 \%$ at age five years, and $23 \%$ at age 12 years.
Table 3 presents estimates from repeated measure mixed effect models for the probability of hospitalization, surgery, and medication use. Results from these models are consistent with the descriptive information presented in Table 2. Estimates of the effect of age indicate that the odds of hospitalization or surgery decreased with increasing age. In contrast, based on the model, an increase in age was associated with an increase in the odds of prescription drug utilization in our sample. Specifically, the model suggests that the probability of hospitalization at age one year among those without a deletion was 0.20 , and 0.05 at age 12 years. In contrast, the probability of use of prescription medication among those without deletion was 0.14 at age one year and 0.99 at age 12 years, and among those with a deletion, it was 0.54 and 0.99 at age one year and 12 years respectively.

\section{Discussion}

AS is a rare condition with an estimated prevalence of 1 in 12,000 to 1 in 20,000 in the US [10]. The most consistent features are global developmental delay marked by intellectual disability, seizures, severe speech impairment, behavior problems, and sleep disturbance, but the presentation and severity of symptoms varies among individuals and changes with age [11-13]. To the best of our knowledge, this is the first study to present the healthcare burden associated with AS, from infancy to age 12 years.

The ASNHS is a large-scale longitudinal study of individuals with AS in the US designed to improve knowledge of the condition and investigate associated morbidity across ages. Individuals in the analyzable sample were younger than 12 years with a mean age of six years and equal sex distribution. On average, we had three years of data for each individual. Our analyses suggest an overall high HRU in this population especially among younger children between 0 and 1 years of age. Hospitalization, surgeries and use of prescription medications to manage various 
Table 2 Healthcare utilization among individuals with AS by age

\begin{tabular}{|c|c|c|c|c|c|c|c|c|c|c|c|c|}
\hline Descriptive & $0-1$ & 2 & 3 & 4 & 5 & 6 & 7 & 8 & 9 & 10 & 11 & 12 \\
\hline$\overline{N^{1}}$ & 301 & 282 & 260 & 234 & 208 & 179 & 155 & 134 & 114 & 92 & 77 & 65 \\
\hline \multicolumn{13}{|l|}{ Hospitalization summary measures } \\
\hline Had hospitalization, \% & 43 & 24 & 21 & 18 & 14 & 13 & 13 & 10 & 12 & 7 & 8 & 11 \\
\hline Hospitalization per year, mean & 1.5 & 1.3 & 1.3 & 1.6 & 1.4 & 1.1 & 1.1 & 1.2 & 1.4 & 1.2 & 1.3 & 1.1 \\
\hline LOS, mean & 6.5 & 3.1 & 2.5 & 2.6 & 4.7 & 3.6 & 3.1 & 2.7 & 2.9 & 1 & 3.4 & 1.5 \\
\hline \multicolumn{13}{|l|}{ Most common reasons for hospitalization } \\
\hline Seizures, \% & 10 & 11 & 10 & 6 & 7 & 5 & 5 & 4 & 3 & 0 & 3 & 1 \\
\hline Lower respiratory infection, \% & 10 & 5 & 1 & 3 & 1 & 1 & 1 & 2 & 3 & 1 & 0 & 0 \\
\hline Surgery, \% & 5 & 3 & 2 & 2 & 1 & 0 & 1 & 2 & 0 & 0 & 0 & 0 \\
\hline \multicolumn{13}{|l|}{ Surgery summary measure } \\
\hline Had surgery, \% & 29 & 21 & 15 & 17 & 9 & 9 & 14 & 8 & 9 & 4 & 8 & 5 \\
\hline \multicolumn{13}{|l|}{ Most common reasons for surgery } \\
\hline Tympanostomy tubes, $\%$ & 10 & 5 & 5 & 3 & 4 & 1 & 2 & 0 & 2 & 0 & 1 & 0 \\
\hline Strabismus, \% & 7 & 9 & 2 & 3 & 1 & 2 & 2 & 1 & 1 & 0 & 0 & 0 \\
\hline Tonsillectomy \& adenoidectomy, \% & 2 & 2 & 5 & 5 & 2 & 2 & 1 & 0 & 1 & 0 & 0 & 0 \\
\hline \multicolumn{13}{|l|}{ Medication summary measures } \\
\hline Number of prescription medications, mean & 2.1 & 2.0 & 2.1 & 2.3 & 2.3 & 2.1 & 2.2 & 2.2 & 2.3 & 2.5 & 2.5 & 2.7 \\
\hline At least one prescription medication, $\%$ & 51 & 59 & 69 & 71 & 76 & 78 & 81 & 81 & 83 & 77 & 78 & 77 \\
\hline Anti-epileptic drugs, \% & 32 & 50 & 61 & 64 & 67 & 69 & 73 & 71 & 72 & 71 & 70 & 69 \\
\hline Anti-gastroesophageal reflux medication, \% & 27 & 15 & 12 & 13 & 12 & 13 & 11 & 12 & 13 & 10 & 12 & 9 \\
\hline Asthma and Allergy medication, \% & 5 & 5 & 7 & 9 & 7 & 6 & 7 & 7 & 8 & 5 & 4 & 6 \\
\hline Antibiotic, \% & 3 & 1 & 4 & 2 & 1 & 1 & 2 & 1 & 1 & 2 & 0 & 2 \\
\hline Sleep medication, $\%$ & 3 & 6 & 9 & 12 & 15 & 18 & 17 & 19 & 18 & 16 & 20 & 26 \\
\hline Psychotropic medication, \% & 1 & 1 & 2 & 6 & 9 & 9 & 13 & 15 & 17 & 22 & 20 & 23 \\
\hline Other, \% & 2 & 1 & 6 & 5 & 6 & 5 & 8 & 6 & 5 & 7 & 10 & 11 \\
\hline Number of non-prescription medications, mean & 1.6 & 1.9 & 1.8 & 1.9 & 1.9 & 2.0 & 2.0 & 2.1 & 2.1 & 2.2 & 2.1 & 1.8 \\
\hline Asthma and Allergy, \% & 3 & 5 & 5 & 6 & 7 & 7 & 8 & 5 & 5 & 5 & 7 & 8 \\
\hline Laxative, \% & 11 & 14 & 15 & 15 & 14 & 14 & 18 & 19 & 17 & 19 & 16 & 19 \\
\hline Sleep medication, \% & 18 & 30 & 31 & 35 & 37 & 33 & 33 & 34 & 31 & 29 & 25 & 23 \\
\hline
\end{tabular}

Notes: ${ }^{1}$ Age is rounded down to the nearest year. The event counts for each age are based on the participants reported age at a specific event. Participant are included in the overall $\mathrm{N}$ (denominator) for each age group until their age at last visit (the oldest age recorded). Participants are only counted once per age. For ages $0-1$ Year, the sum of the number of unique prescription/non-prescription medications taken at age 0 and at age 1 is summarized

symptoms were common. Our data suggests that younger children, often in the first year of life, tended to experience more surgeries, hospitalizations, and longer hospital stays than older children. The use of prescription medications increased with age in this cohort and by age six almost $80 \%$ of children were using at least one medication.

Our analyses support the heterogeneity of the condition. It appears that the various symptoms were managed through a combination of hospital-based interventions and prescription medications. Seizures are one of the most common symptoms associated with AS [11], and antiepileptic drugs (AEDs) are the accepted first-line treatment for managing seizures in these individuals. In this study, we found that AEDs were the most commonly used class of medication, regardless of age, consistent with the high incidence of seizures in this population.

Medications to treat sleep disturbance were the other common category. Sleep difficulties may manifest as increased sleep latency, decreased total sleep time, abnormal sleep-wake cycle, and frequent nocturnal awakening [11]. Some studies suggest that sleep disturbances are more common among young children 2 to 9 years of age and improve with age, while others report that they continue into adolescence and adulthood [1]. We found that use of sleep medications increased with age. Use of melatonin, a commonly used non-prescription medication, was $18 \%$ in the first year, peaked at age $8(34 \%)$ and continued to be high into early adolescence (23 to $34 \%$ ). 
Table 3 Repeated measures mixed effect model of probability of use of healthcare utilization

\begin{tabular}{|c|c|c|c|}
\hline & Hospitalization & Surgery & Prescription medication \\
\hline $\mathrm{N}$ & 298 & 297 & 297 \\
\hline Number of observations & 2384 & 2387 & 2387 \\
\hline Intercept & $\begin{array}{l}-1.222^{*} \\
{[0.1740]}\end{array}$ & $\begin{array}{l}-1.599^{*} \\
{[0.1936]}\end{array}$ & $\begin{array}{l}-2.628^{*} \\
{[0.4812]}\end{array}$ \\
\hline Age & $\begin{array}{l}-0.149^{*} \\
{[0.0452]}\end{array}$ & $\begin{array}{l}-0.079 \\
{[0.0436]}\end{array}$ & $\begin{array}{l}0.822^{*} \\
{[0.1697]}\end{array}$ \\
\hline Molecular genotype & $\begin{array}{l}0.384^{*} \\
{[0.1958]}\end{array}$ & $\begin{array}{l}0.176 \\
{[0.2143]}\end{array}$ & $\begin{array}{l}1.166^{*} \\
{[0.5341]}\end{array}$ \\
\hline Age* Molecular genotype. & $\begin{array}{l}-0.056 \\
{[0.0497]}\end{array}$ & $\begin{array}{l}-0.078 \\
{[0.0472]}\end{array}$ & $\begin{array}{l}0.808^{*} \\
{[0.2230]}\end{array}$ \\
\hline
\end{tabular}

Notes: A repeated measures mixed effect binary model was assessed for each healthcare resource. Each column represents a separate model and the column heading indicates the dependent variable. Each model predicts the probability of an event (e.g., hospitalization, surgery or use of prescription medications) controlling for molecular genotype. $\mathrm{N}$ refers to unique number of individuals and the number of observations refers to the total number of years of available data for all individuals for an analysis. Standard errors are in parenthesis. The main coefficient of interest is age and it depicts how utilization changes with age. Based on the models above, a positive coefficient for age suggests that utilization increases with an increase in age and a negative coefficient suggests a decrease in utilization with an increase in age

*Significant at $p<0.05$

Individuals with AS may have behavioral issues, such as hyperactivity, impulsivity, and aggressive behaviors [11]. We observed increasing use of behavioral/psychiatric (psychotropic) medications with age. Use of medication to treat GERD was highest in the first year of life, after which use decreased, mirroring the typical age when this issue is most problematic.

This study has several limitations. The population was skewed towards individuals younger than five years old and the mean number of data points per individual was only three. The ASNHS study did not record any information on use of outpatient care (e.g., visits to primary care physicians, neurologists, geneticists, psychiatrists, and other specialists). While not as costly as hospitalization, outpatient care tends to be one of the largest volume drivers of healthcare burden. We were unable to determine whether the reported surgeries were performed in an outpatient or an inpatient setting. Since the data used in these analyses were collected via caregiver (either primary or informal) interviews, the HRU was likely underreported due to recall failure and should be considered a minimum estimate, particularly true for medication use. In addition, we are using the event dates to create longitudinal history of healthcare utilization and misreporting is likely to be higher for medication use and as such the medication results should be interpreted in the light of these limitations. Replication of the findings in this study using claims data or administrative sources will help to corroborate these results.

\section{Conclusions}

In summary, this is the first study to describe how the HRU varies with age in children with AS. We have shown overall high HRU use as well as different types of HRU, to manage a constellation of heterogeneous symptoms and co-morbidities. The high healthcare burden for these individuals and their families can be demonstrated by the high hospitalization and surgery rates, especially in the first year of life. We also described how the use of medications increased with age, especially for conditions such as seizures, sleep disturbance, and behavioral issues. Future studies are required to provide a holistic view on the HRU use in both children and adults and evaluate the overall impact on caregivers and the healthcare system.

\section{Acknowledgements}

The ASNHS was supported by NIH U54 RR019478 (awarded to Arthur L. Beaudet) from the National Center for Research Resources (NCRR) and NIH U54 HD061222 (awarded to Alan Percy) from the National Institute of Child Health and Human Development (NICHD), both components of the National Institutes of Health (NIH).

\section{Authors' contribution}

All authors read and approved the final manuscript. NK designed the analyses, interpreted the data, and wrote the manuscript. RC helped designed the analyses and contributed to the manuscript. WHT collected the data, helped interpret the data, and contributed to the manuscript. RT analyzed the data. LMB collected the data, helped interpret the data, and contributed to the manuscript.

Funding

The ASNHS was supported by NIH U54RR019478 and U54HD061222.

Availability of data and materials

Derived data that can help generate results can be provided from the corresponding author on reasonable request.

\section{Ethics approval}

This study was approved by the institutional review boards at each of the institutions where the data were obtained.

Consent for publication

Not applicable.

\section{Competing interests}

Dr. Khan is a paid consultant for Ovid Therapeutics Inc. (Ovid) Ms. Cabo is a paid employee of Ovid. Dr. Tan is participating in clinical trials and has received research supported from Ovid. Ms. Tayag is a paid employee of PROMETRIKA, LLC. PROMETRIKA was paid by Ovid to perform statistical 
analyses for this paper. Dr. Bird is participating in clinical trials supported by Ovid.

\section{Author details}

${ }^{1}$ RWEC LLC, 73 Walsingham, Mendham, NJ 07945, USA. ${ }^{2}$ Division of Genetics \& Genomics, Boston Children's Hospital; Harvard Medical School, 300 Longwood Avenue, Boston, MA, Boston, MA 02115, USA. ${ }^{3}$ PROMETRIKA, LLC, 100 Cambridgepark Drive, 2nd Floor, Cambridge, MA 02140, USA.

${ }^{4}$ Department of Pediatrics, San Diego; Clinical Genetics / Dysmorphology, Rady Children's Hospital San Diego, University of California, 3020 Children's Way \#5031, San Diego, CA 92123, USA.

Received: 24 May 2019 Accepted: 24 September 2019

Published online: 04 November 2019

\section{References}

1. Wheeler AC, Sacco P, Cabo R. Unmet clinical needs and burden in Angelman syndrome: a review of the literature. Orphanet J Rare Dis. 2017;12(1):164

2. Thomson AK, Glasson EJ, Bittles AH. A long-term population-based clinical and morbidity profile of Angelman syndrome in Western Australia: 19532003. Disabil Rehabil. 2006;28(5):299-305.

3. Dominguez-Berjon MF, Zoni AC, Esteban-Vasallo MD, Sendra-Gutierrez JM, Astray-Mochales J. Main causes of hospitalization in people with Angelman syndrome. J Appl Res Intellect Disabil. 2018;31(3):466-9.

4. Khan N, Cabo R, Tan WH, Tayag R, Bird LM. Healthcare burden among individuals with Angelman syndrome: Findings from the Angelman Syndrome Natural History Study. Mol Genet Genomic Med. 2019:e734.

5. Tan WH, Bacino CA, Skinner SA, Anselm I, Welge R, Carlin A, et al. Angelman syndrome: mutations influence features in early childhood. Am J Med Genet A. 2011;155(1):81-90.

6. Lossie AC, Whitney MM, Amidon D, Dong HJ, Chen P, Theriaque D, et al. Distinct phenotypes distinguish the molecular classes of Angelman syndrome. J Med Genet. 2001;38(12):834-45.

7. Varela MC, Kok F, Otto PA, Koiffmann CP. Phenotypic variability in Angelman syndrome: comparison among different deletion classes and between deletion and UPD subjects. European journal of human genetics : EHHG. 2004;12(12):987-92.

8. Moncla A, Malzac P, Voelckel MA, Auquier P, Girardot L, Mattei MG, et al. Phenotype-genotype correlation in 20 deletion and 20 non-deletion Angelman syndrome patients. Eur J Hum Genet. 1999;7(2):131-9.

9. Gentile JK, Tan W-H, Horowitz LT, Bacino CA, Skinner SA, Barbieri-Welge R, et al. A neurodevelopmental survey of Angelman syndrome with genotypephenotype correlations. Journal of developmental and behavioral pediatrics : JDBP. 2010;31(7):592-601.

10. NORD. National Organization for Rare Disorders. https://rarediseases.org/ rare-diseases/angelman-syndrome/ 2018.

11. Williams CA, Beaudet AL, Clayton-Smith J, Knoll JH, Kyllerman M, Laan LA, et al. Angelman syndrome 2005: updated consensus for diagnostic criteria. Am J Med Genet A. 2006;140(5):413-8.

12. Smith JC. Angelman syndrome: evolution of the phenotype in adolescents and adults. Dev Med Child Neurol. 2001;43(7):476-80.

13. Prasad A, Grocott O, Parkin K, Larson A, Thibert RL. Angelman syndrome in adolescence and adulthood: a retrospective chart review of 53 cases. Am $J$ Med Genet A. 2018;176(6):1327-34.

\section{Publisher's Note}

Springer Nature remains neutral with regard to jurisdictional claims in published maps and institutional affiliations.

Ready to submit your research? Choose BMC and benefit from:
- fast, convenient online submission
- thorough peer review by experienced researchers in your field
- rapid publication on acceptance
- support for research data, including large and complex data types
- gold Open Access which fosters wider collaboration and increased citations
- maximum visibility for your research: over 100M website views per year
At BMC, research is always in progress.
Learn more biomedcentral.com/submissions

